\title{
Radiolucent retractor for angiographic analysis during hybrid congenital cardiac procedures
}

\author{
Gareth J. Morgan, MB, BaO, BCh, MRCPCH, MPhil, Karen Clarke, RN, Christopher Caldarone, MD, and \\ Lee N. Benson, MD, FRCPC, Toronto, Ontario, Canada
}

Management of congenital heart disease by using a combination of surgical and interventional cardiology skills is a growing field, and as such, many technical innovations are being described. ${ }^{1-4}$

One key area is the interplay between the sterile surgical field and the imaging equipment required for angiographic analysis. Stable positioning of surgical clamps, drains, and retractors can be challenging to adjust for high-quality imaging of the anatomy. As part of a strategy to improve the procedure, our group has devised and implemented a radiolucent sternal retractor (Finochietto infant retractor design) to allow improved angiographic visualization without compromising the surgical field.

\section{DISCUSSION}

The dimensions of the radiolucent spreader are identical to a standard steel infant Finochietto retractor; however, the device is constructed almost entirely from polyetheri-

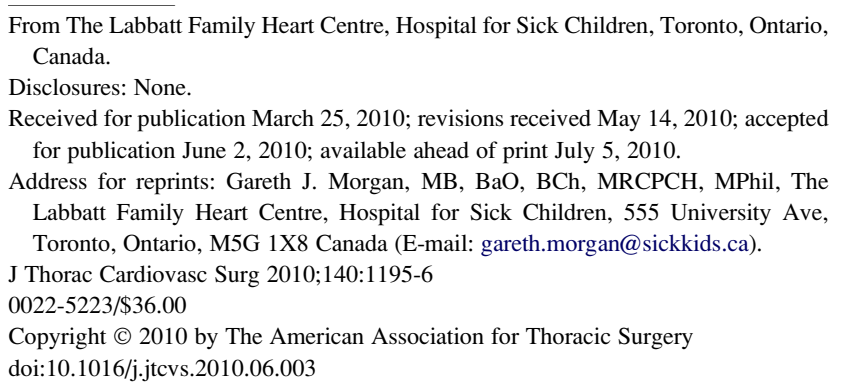

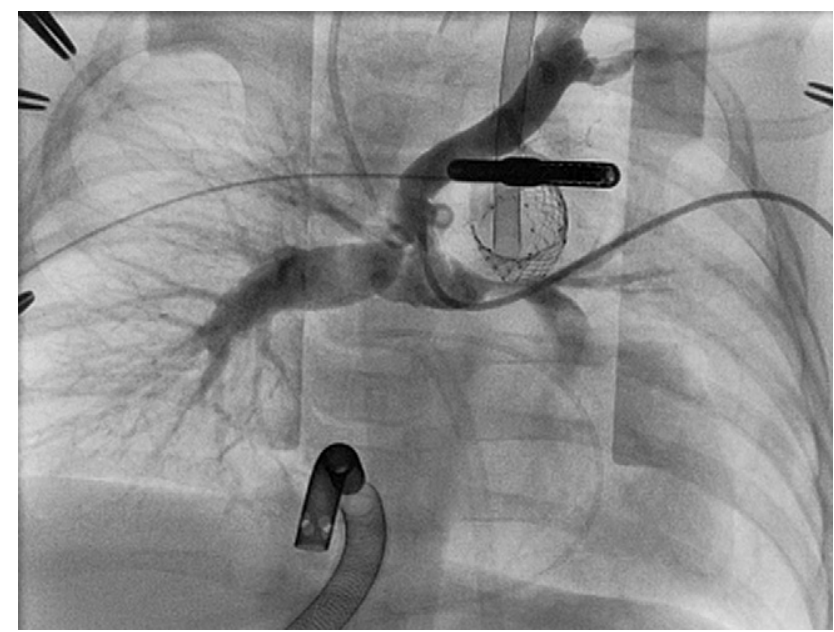

FIGURE 2. The radiolucent retractor in use during a stage 2 hybrid hypoplastic left heart syndrome procedure. The projection is a straight posteroanterior with the catheter placed in the Glenn anastomosis directly through the open chest. The arms of the retractor can just be delineated, allowing angiographic visualization of the innominate vein and distal branch pulmonary arteries. A significant stenosis of the left pulmonary artery can be seen.

mide, a thermoplastic with excellent machinability and mechanical properties, which is also heat stable for sterilization in an autoclave (Figure 1). A part of the hinge mechanism is made from stainless steel to ensure longevity and maintain smooth operation of the hinge over multiple procedures. Its radiolucency aids the ease and quality of the angiographic analysis (Figure 2). We believe that innovative solutions
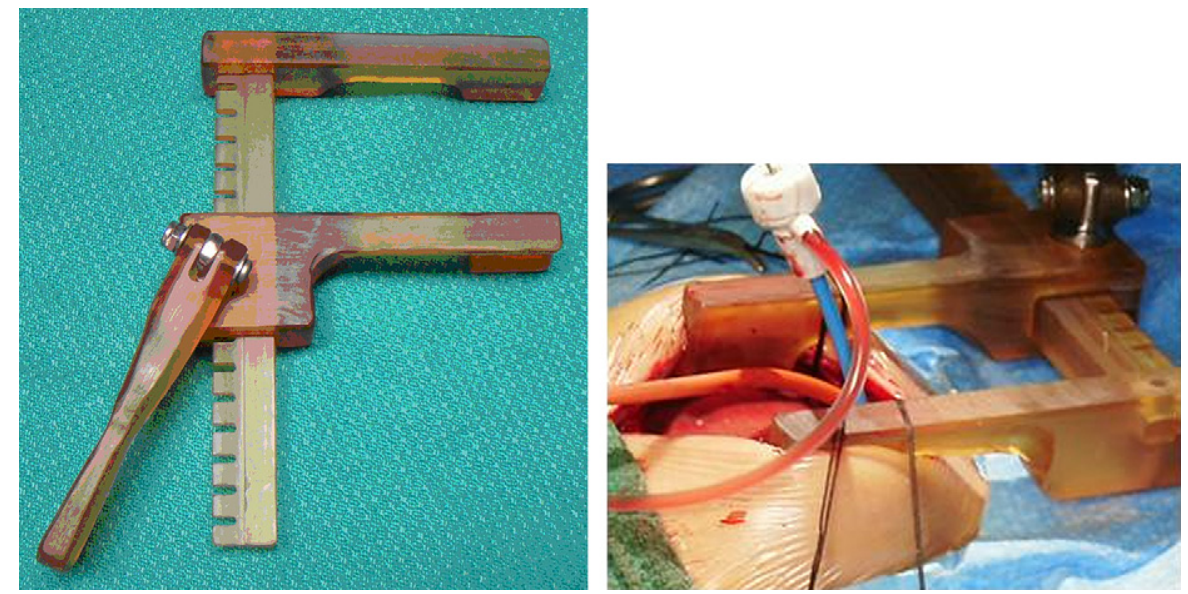

FIGURE 1. Left, The thermoplastic radiolucent Finochietto infant retractor. Right, The retractor in use during stage 1 of a hybrid procedure for hypoplastic left heart syndrome. Note the $6 \mathrm{~F}$ sheath placed through the chest into the main pulmonary artery for ductal stent placement. 
such as this are important in the continued development of hybrid technologies for use in patients with in congenital and structural heart disease.

\footnotetext{
References

1. Sawdy JM, Gocha MD, Olshove V, Chisolm JL, Hill SL, Phillips A, et al. Radiation protection during hybrid procedures: innovation creates new challenges. J Invasive Cardiol. 2009;21:437-40.
}

2. Chen Q, Parry AJ. The current role of hybrid procedures in the stage 1 palliation of patients with hypoplastic left heart syndrome. Eur J Cardiothorac Surg. 2009;36: 77-83.

3. Galantowicz M, Cheatham JP. Lessons learned from the development of a new hybrid strategy for the management of hypoplastic left heart syndrome. Pediatr Cardiol. 2005;26:190-9.

4. Venugopal PS, Luna KP, Anderson DR, Austin CB, Rosenthal E, Krasemann T, et al. Hybrid procedure as an alternative to surgical palliation of high-risk infants with hypoplastic left heart syndrome and its variants. J Thorac Cardiovasc Surg. 2010;139:1211-5.

\title{
Palliative role of percutaneous radiofrequency ablation for severe hemoptysis in an elderly patient with inoperable lung cancer
}

\author{
Alessandro Baisi, MD, ${ }^{\mathrm{a}}$ Federico Raveglia, MD, ${ }^{\mathrm{a}}$ Matilde De Simone, MD, $\mathrm{PhD},{ }^{\mathrm{b}}$ and \\ Ugo Cioffi, $\mathrm{MD}, \mathrm{PhD},{ }^{\mathrm{b}}$ Milan, Italy
}

Surgical resection remains the standard therapeutic treatment for patients with resectable non-small cell lung cancer and for selected patients with limited pulmonary metastases from extrathoracic tumors, even if only a small number of patients are suitable for potentially curative resection. ${ }^{1,2}$ Percutaneous image-guided radiofrequency ablation (RFA) is a minimally invasive therapeutic option that has been successfully applied to local control of tumors in different organs including the lung. ${ }^{3,4}$ This technique has recently been recognized as the primary therapy in patients who are not candidates for limited surgery or radiotherapy and can be used to treat recurrent lesions. ${ }^{4}$ The procedure is well tolerated and the complication rate is acceptable even when considering the treatment of large masses. ${ }^{4,5} \mathrm{We}$ report a case of an elderly patient with advanced lung cancer leading to severe and recurring hemoptysis that was successfully treated with RFA.

\section{CLINICAL SUMMARY}

An 82-year-old woman was referred to our department with right lung cancer complicated by severe and recurring hemoptysis necessitating repeated blood transfusions. The tumor was $6 \times 6 \mathrm{~cm}$ in size, located in the peripheral paren-

From the Thoracic Surgery Unit, ${ }^{a}$ Ospedale San Paolo, and the Department of Surgery, ${ }^{\mathrm{b}}$ Fondazione IRCCS Ospedale Maggiore Policlinico Mangiagalli e Regina Elena, University of Milan, Milan, Italy.

Disclosures: None.

Received for publication Nov 17, 2009; revisions received Jan 8, 2010; accepted for publication Jan 18, 2010; available ahead of print July 2, 2010.

Address for reprints: Alessandro Baisi, MD, Thoracic Surgery Unit, Ospedale San Paolo, Via A. di Rudinì, 8, 20142 Milano, Italy (E-mail: alessandro.baisi@unimi.it). J Thorac Cardiovasc Surg 2010;140:1196-7

0022-5223/\$36.00

Copyright (c) 2010 by The American Association for Thoracic Surgery doi:10.1016/j.jtcvs.2010.01.049 chyma of the lower lobe, with pathologic hilar and mediastinal lymph nodes. Three months earlier, she had been excluded from both surgery and medical treatment owing to the tumor stage (IIIB) and respiratory and cardiac comorbidities. Several bronchoscopic examinations were performed showing blood in the airways without any evident endobronchial source of the bleeding. Endobronchial cauterization was unfeasible to control the hemoptysis because there was no evident endobronchial source of the bleeding. No bronchial or pulmonary vessels supplying the mass were identified in an arteriogram, and embolization was also impossible. In the hope of controlling the bleeding by sclerosing the tumor, we attempted a percutaneous RFA, despite the size of the mass and the tumor stage. The procedure was performed under a nonenhanced computed tomographic (CT) scan by RF 3000 Radiofrequency Generator with a 16-gauge, $15-\mathrm{cm}$ long, $4.0-\mathrm{cm}$ array diameter LeVeen CoAssess Electrode (Radiotherapeutics, Boston Scientific Corporation, Natick, Mass), starting from 30 up to 160 watts (Figure 1) and repeated more in depth in the mass starting from 30 up to 120 watts (Figure 2). The hemoptysis was successfully controlled after the procedure. A minimal pleural effusion without pneumothorax occurred. At the 6-month follow-up, the patient was free from bleeding and the mass was reduced to $5 \times 5 \mathrm{~cm}$. One year after the procedure the patient died of distant metastases.

\section{DISCUSSION}

The safety and feasibility of percutaneous RFA for unresectable lung cancers have now been considered by several authors. ${ }^{1,2,5}$ Survival time and efficacy of the procedure are significantly longer in patients with completely ablative tumors. ${ }^{2}$ Tissue ablation adequacy depends 